\section{REFORM IN MEDICAL NOMENCLATURE.} To the Editor of The Lancet.

SIR,-All liberal-minded members of the medical profession have, doubtless, learned with satisfaction that the approaching consideration by Parliament of the bill recently prepared by the Council of "The Provincial Medical and Surgical Association," will afford a favourable opportunity of effecting some improvement in the social status of those of our professional brethren popularly known as " general practitioners."

The bill, which is yet in embryo, is still susceptible of important emendations. I am glad to find that the contemplated measure of medical reform will, if sanctioned by the legisiature, abolish the inappropriate and offensive title which the Court of Examiners of the Society of Apothecaries at present inflicts upon the candidate, who, aft er subjecting himself to a comprehensive curriculum of study, and subsequently passing a rigid examination in medicine and several of the allied sciences, has been declared to possess a competent knowledge of his profession; but the licentiate has hitherto only regarded the certificate, or licence, received on the occa. sion as "a document it is desirable to hide in the secret recesses of his écritoire."

All must admit the utter inadequacy of the title of "Apothecary" as the characteristic designation of those legally authorized to discharge the multifarious and highly responsible functions appertaining to the office of the medical advisers of at least 9999 out of every 10,000 of "the millions of people in this country subject to the infirmities and diseases incidental to the highest and most complicated part of organized nature."

Are not men so eminently characterized by intelligence and scientific attainments, and who, moreover, unequivocally manifest so much philanthropy in the performance of very onerous and ardnous duties, entitled to occupy a better position in the social scale than that which they now have?

Considering the nature of the examination which candidates for the licence obtained at "the Hall" undergo, it is certainly most unjust to impose upon them a title derived from the secondary, and almost menial, functions which they perform, and which, in fact, are more frequently performed by deputies than by themselves.

I humbly suggest that it is highly desirable the new Examining Board should be a faculty authorized to confer the degree of Bachelor of Medicine and Surgery upon those who become members of the College of Surgeons, and also obtain the triple licentiateship of medicine, surgery, and midwifery.

The new order of general practitioners would then have, in common parlance, the courtesy title of Doctor,* which, I would observe, is the ordinary designation of the medical adviser of all classes in Germany, and in other parts of Europe.

While the proposed courtesy Doctor would probably be considered by some persons of merely analogous value to the spurious title of Esquire, accorded, even by the highest classes in the community, to professional men and persons of patrician rank, not actually esquires by creation, office, or legal privilege, the great majority of the members of the profession would, I believe, consider the Bachelorate I suggest as well calculated to improve the status of those who will enter into general practice under the new régime.

The M.B.S. would occupy a position nearly equal to that of the M.B. proceeding to the degree of M.D., upon the attainment of which he possesses the legal rank of Doctor and Physician.

All circumstances considered, I think the proposition will not be deemed an unreasonable one, more especially after taking into consideration the fact that a large proportion of the M.D.'s in practice have purchased their diplomas at Giessen, Leipsic, St. Andrew's, Aberdeen, cr other Doctorfactories, where there is either no examination, or the prescribed ordeal is not superior, if even equal, to that undergone by the physician-apothecaries, who are now inappropriately dubbed apothecaries by the medical corporation to which the public is so largely indebted for the vast improvement effected in the education of the "general practitioner."

Some elaborately-framed and well-digested propositions for the substitution of a Doctorate in surgery for the membership

* When the authority to practise has been acquired, the German Doctor has full power to officiate in medicine, surgery, and midwifery. By Bavarlan decree, passed in 1843 , a subordinate class of practitioners was partially suppressed and declared unqualified to practise either surgery, medicine, or midwifery.

$t$ The eldest sons of Doctors of Divinity are in this category. of the Royal College of Surgeons, have been lately promulgated by the medical profession of the Isle of Man, and are worthy of careful consideration.

I believe that a suggestion somewhat similar to that which I have offered in reference to the general adoption of the title of Doctor, would have emanated from the Provincial Medical and Surgical Association, if a large portion of the presidents and secretaries of the branch associations had not been graduates of some of the universities to which I have alluded, and had not consequently an interest in discouraging attempts to effect changes which would counteract their efforts to establish themselves in what they consider to be a higher grade than that to which the immense majority of their rural brethren belong.

The contemplated amendment of the laws which regulate the medical profession and the medical polity of the kingdom, will fall very far short of what expediency, reason, and justice dictate, if it does not considerably improve the status of the members of the general body of the profession, by placing them on as good a footing in society as the general practitioner in other European countries.

If the members of the new college are merely to have the name and style of Licentiates, all idea of materially improving the social position of the general practitioner may be at once abandoned.

The establishment of a Royal College of "Medical Practitioners," in lieu of the Society of Apothecaries, as suggested by Mr. Brookes at the Shropshire Medical Reform ineeting, would be much better calculated to effect the object which the framers of "the bill" profess to have in view, than the resuscitation of an order of bipeds to be known as licentiates.

Instead of perpetuating the degradation of the larger portion of the profession, by maintaining broadly-marked distinctions for the purpose of preserving a medical aristocracy, every available means should be employed to qualify the rank and file of the profession to move in the higher grades of society on more equal terms than they do at present. I have the honour to be,

Your obedient humble servant

Stowmarket, March 1859 F. J. SANDFORD.

\section{I D W I FE'S M I D W I F E R Y. To the Editor of The Lancet.}

Sir,-At five o'clock A.M., on the 29th of February, I was requested to visit a woman, aged forty, who, her husband informed me, had been delivered of her eighth child by a midwife between eight and nine o'clock the previous evening, and was now suffering from a discharge, or something of that kind. On entering the patient's room, I soon discovered the state of affairs. Everything appeared saturated with blood, the woman's skin was cold and clammy, the pulse not perceptible at the wrists, and the uterus distended. I immediately gave her some gin, that being the only stimulant in the house, introduced my hand, and removed a quantity of coagulated blood, also a portion of placenta between three and four inches square, which was slightly adherent towards the fundus; and by pressing externally with my right hand, while I gently withdrew my left, I got the uterus to contract, though feebly. But it was too late, for $I$ had but just time to apply a tight bandage, under which I placed a pad, before my patient expired. During the time I was thus occupied, which was little more than five minutes, the midwife was talking about her experience, and saying she considered it a false conception, as she had removed all the afterbirth piecemeal, on account of its being rotten, and she was sure she had done her best; but to which I replied, I supposed she had, but it was a pity she had not sent for a medical man earlier.

The husband, not feeling satisfied about his wife's death, wished for a coroner's inquest-a wish I rather encouraged, in the first place to clear myself, and in the next to expose the ignorance and negligence of the midwife, who had allowed the woman to continue flooding from before nine o'clock P.M. till five A.M.

An inquest was accordingly held on the 5th instant, when I had no hesitation in saying the woman's death was caused by flooding, through the gross ignorance and neglect of the midwife. The room was cleared, and after some time, a verdict of "Died of natural causes" was returned, with a polite caution that the midwife should in future send for proper medical assistance earlier. I shall not attempt to say anything about the verdict, fearing I might say too much; but must $I$ bow my head, and in future pretend to believe that all causes of death are natural ? 
I should not have troubled you with this letter, but since the inquest there have been various reports afloat. Some think the inquest was altogether unnecessary, and that the doctor was too partial towards his own profession, and vindictive against the poor midwife; others think I have only done my duty. And as a young beginner, I should esteem it a great kindness, if you would inform me whether I shall be right in always making such cases as public as possible, or let them alone to die a natural death, and remain quiet at the time my fellow-creatures are losing their lives, when a little precaution might save them? This midwife informed the jury she took out her degrees the year George IV. died, and that she had attended several hundred cases. This is the second woman she has lost in the same family.

If you think this letter worthy of insertion in your journal, you will oblige, by so doing,

King's-row, Walworth, March, 1852. Yours faithfully, $\quad$ LEwIS NEWNHAM, M.D.

\section{INVERSION OF THE UTERUS.}

\section{To the Editor of THE LANCET.}

SIR,-Mr. Forbes's paper, read before the Royal Medical and Chirurgical Society, on the 23rd of March, calls to my recollection a case of inversion of the uterus, which was successfully operated upon some years ago by a midwife at Coventry.

The subject of the operation was, I believe, an Irishwoman, and was attended in her confinement by a female accoucheur, who, after pulling away at the cord, and extracting the placenta, was greatly surprised to find a large tumour protrude from the vagina: not knowing the nature of which, and being unable to return it, she boldly decided upon taking it away; and adopted the simple, but very effectual, expedient of cutting it off with a razor. In this case there appears to have supervened neither the much-dreaded hæmorrhage, nor peritonseal inflammation, for, if I remember the history of the case correctly, the woman was quite well and walking about Coventry fair in a fortnight or three weeks afterwards. The excised uterus and apperidages are, or were, in the Museum of the Queen's College at Birmingham.

I have seen inversion of the uterus in the cow (technically called "shooting the reed") successfully treated by keeping the hind quarters well raised, and applying a species of truss. But the great object is to prevent the propulsive efforts afterwards by large doses of opium.

As Dr. Tyler Smith remarked, "some modification of a truss might be useful in obstetric practice."

Your obedient servant,

Wolverhampton, April 1852. Georae EDWardes, Surgeon to the South Staffordshire Hospital.

\section{MEETINGS OF THE MEDICAL SOCIETIES IN LONDON DURING 'THE ENSUING WEEK.}

Nors.-When the day of the month is not specified, no meetings take place,

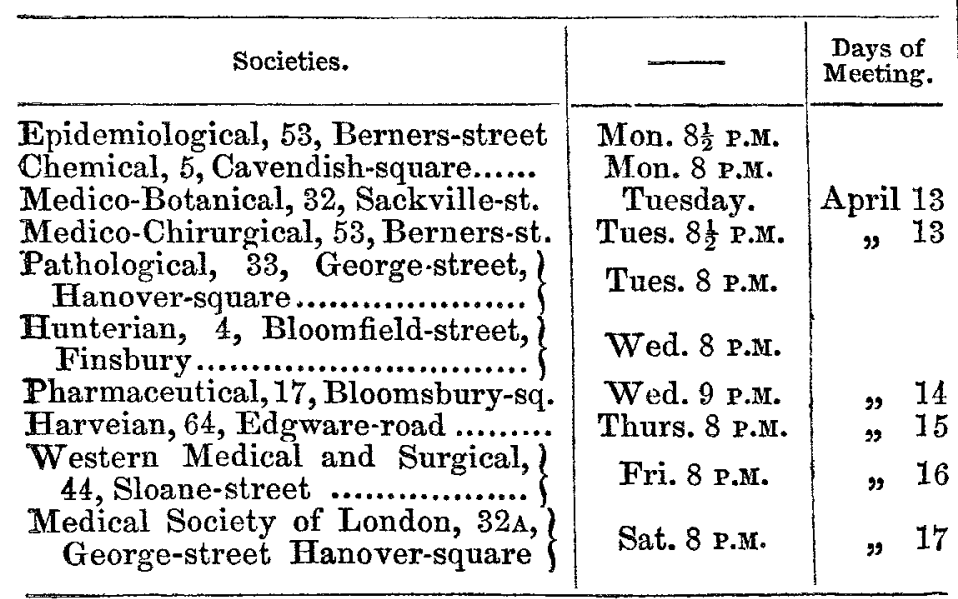

Hydrophozta. - A man, residing at Epinay, in France, was lately bitten by a dog; he did not consider there was any danger, and contented himself with the application of a piece of rag to the wound. About three weeks afterwards he was seized with trembling. He was then taken to an hospital, where he received every attention, but he died the next day, after several hours of intense agony.

\section{Anerical Aetos.}

Royal College of Physicians.-At the quarterly meeting of the Comitia Majora, held on Monday, April 5th, the following gentlemen, having undergone the necessary examinations for the diploma, were admitted members of the college:-

Dr. Henrt Folkard, Old Brompton.

Dr. Liebermann, Clapham-road.

Dr. Prout, Royal Hospital, Chelsea.

Dr. SaLter, Montague-street, Russell-square.

Also-

Dr. Osbors, Southampton,

was admitted an Extra-Licentiate.

Royal College of Surgeons.-The following gentlemen, having undergone the necessary examinations for the diploma, were admitted Members of the College, at the meeting of the Court of Examiners, on the 2nd inst.:-

Burke, John Mathew, London.

Carr, George William, Kincardine, Upper Canada.

Crossley, Charies Richard, Ashby-de-la-Zonch, Leicestershire.

Curannven, John Brendon, Highgate.

Evans, William, Anglesey.

Gryils, Wilutam Richard, Sydney, New South Wales.

Hatnes, William, Hon. East India Company's Service, Bengal.

IzoD, IBBERSON, Birmingham.

Jeeves, Wildiam Youva, Sharrow Grange, Yorkshire.

Lee, Charles, Woodbridge, Suffolk.

Symmons, Robert Francis, Bures, Suffolk.

Apothecaries' Hall.-Names of gentlemen who passed their examination in the science and practice of medicine, and received certificates to practise, on

$$
\text { Thursday, April 1st, } 1852 .
$$

Beline, William Field, Great Yarmouth.

Birks, George V AUte, Manchester.

Couch, Thomas Quilier, Polpero, Cornwall.

Crossley, Charles Richard, Ashby-de-la-Zouch.

Hedger, Alfred, South-street, West-square.

Lomax, Arthor Robert, Hereford.

Mathews, Henry John Davis, Denmark-hill.

Nelson, Joseph Donn, Exeter.

White, Thomas, Chester.

Office-Bearers of the Epidemiological Socretr. - Session 1852-3. - President: Benjamin Guy Babington, M.D., F.R.S. - Vice-Presidents: Thomas Add on M.D.; Richard Bright, M.D., F.R.S.; Sir B. C. Brodie, Bart., F.R.S; Sir W. Burnett, Knt., K.C.B., K.C.H., F.R.S.; Sir C. M. Clarke, Bart., M.D., F.R.S.; Rev. Thomas Dale, M.A., Canon Res. of St. Paul's; R. D. Grainger, Esq., F.R.S.; Sir Charles Hastings, M.D., Worcester; Sir John Liddell, M.D. C.B., F.R.S.; Sir James M`Grigor, Bart., K.C.B., K.C.T.S.; John Nussey, Esq.; John Propert, Esq.; G. I. Roupell, M.D., F.R.S.; Thomas Southwood Smith, M.D.; Colonel Sykes, V.P.R.S. ; Thomas Watson, M.D. - Treasurer: Thomas Addison, M.D., Vice-President.-Honorary Secretaries: J. 0. M'William, M.D., F.R.S., R.N.; J. H. Tucker, Esq.-Members of Council: C. A. Aikin, Esq.; G. H. Barlow, M.D.; James Bird, M.D.; Samuel Brown, Esq.; A. Bryson, M.D., R.N.; C. Finch, M.D.; R. Greenhalgh, Esq.; A. H. Hassall, M.D.; Edward Headland, Esq.; A. Helsham, M.D.; Thomas Hunt, Esq.; Waller Lewis, M.B., F.G.S.; J. F. Marson, Esq.; Gavin Milroy, M.D.; A. Nisbett, M.D., R.N.; George Pilcher, Esq.; E. C. Seaton, M.D.; F. Sibson, M.D., F.R.S.; E. Sieveking, M.D.; Professor Simonds, R.V.C.; J. Snow, M.D.; G. J. Squibb, Esq.; William Edward Swaine, M.D.; C. R. Walsh, Esq.

Cod-tiver OrL.-The Columbo Observer states that the physicians of India contend that the virtue for which cod-liver oil is so famous, is not confined to the oil extracted from cod-liver, but is equally shared by all fish yielding oil, including the common whale oil. The liver of the seer fish is also deemed by the medical gentlemen of India to possess great restorative qualities.

Hospital Staff.-Assistant-Surgeon J. R. Brush, M.D., has been promoted from the 2nd Dragoons to be StaffSurgeon of the Second Class, vice Dixon, promoted to the 57th. 